Research Article

Janusz Skrzypacz* and Marcin Bieganowski

\title{
Investigations of drilled and multi-piped impellers cavitation performance
}

https://doi.org/10.1515/eng-2019-0032

Received Feb 11, 2019; accepted Apr 08, 2019

Abstract: The industry needs the rotodynamic pumps operating with ultra-low specific speed and relatively low flow rate more often. Designing of such structures on acceptable efficiency level is extremely difficult and require nonstandard approach to design as for example: drilled impeller or patented by author multi-piped impeller. Such pump elements are very easy to manufacture and operate with relatively high efficiency, but cavitation behavior is unknown.

This paper focuses on experimental research in order to determine the cavitation characteristics of the drilled impellers and multi-piped impellers. The test rig was presented. Impeller models were made by means of SLS Rapid Prototyping methods. Additionally, CFD calculations were presented in order to determine static pressure distribution in the inlet sections of the investigated impellers.

Keywords: drilled impeller, multi-piped impeller, cavitation, CFD

\section{Symbols}

$\begin{array}{ll}c_{s} & \text { fluid velocity at section pipeline, } \mathrm{m} / \mathrm{s} \\ c_{t} & \text { fluid velocity at discharge pipeline, } \mathrm{m} / \mathrm{s} \\ g & \text { gravity, } \mathrm{m} / \mathrm{s}^{2} \\ H & \text { pump head, } \mathrm{m} \\ n_{q} & \text { kinematic specific speed, } \mathrm{rpm} \\ N P S H_{r} & \text { net positive suction head (required), } \mathrm{m} \\ p_{b} & \text { barometric pressure, Pa } \\ p_{m s} & \text { gauge pressure in the pump inlet, } \mathrm{Pa}\end{array}$

\footnotetext{
${ }^{\star}$ Corresponding Author: Janusz Skrzypacz: Wroclaw University of Science and Technology, Department of Mechanical and Power Engineering, ul. Wybrzeże Wyspiańskiego 27, 50-370 Wrocław, Poland; Email: janusz.skrzypacz@pwr.edu.pl

Marcin Bieganowski: Wroclaw University of Science and Technology, Department of Mechanical and Power Engineering, ul. Wybrzeże Wyspiańskiego 27, 50-370 Wrocław, Poland; Email: marcin.bieganowski@pwr.edu.pl
}

\author{
$p_{m t} \quad$ gauge pressure in the pump outlet, $\mathrm{Pa}$ \\ $P_{u} \quad$ hydraulic power, $\mathrm{W}$ \\ $p_{v} \quad$ fluid vapor pressure, $\mathrm{Pa}$ \\ $P_{w} \quad$ power on the pomp shaft, W
}

\section{Greek symbols}

$\beta_{1}$ impeller inlet angle, deg

$\eta$ pump efficiency

$\rho$ density, $\mathrm{kg} / \mathrm{m}^{3}$

\section{Introduction}

Modern world industry, especially chemical one, requires pumps that will be able to operate in range of extremely low specific speed $\left(n_{q}<10\right)$ with acceptable level of efficiency. Designing rotodynamic pumps operating in mentioned range of parameters is extremely difficult because of low performance [1-3]. Such structures must be designed in non-standard way.

During the work over this problem, the idea of drilled impeller [4] was developed. The new solutions of the rotodynamic impellers were introduced as:

1. Drilled impeller with side holes [5].

2. Multi-piped impeller [6].

The numerous researches confirmed positive operation of such structures form energy consumption point of view $[7,8]$, but cavitation performance was unknown.

The main aim of this project was determining cavitation characteristics of the pump impellers listed above, designed in non-standard way. The special test rig was described and results of measurements were presented. Additionally, in order to interpret better the results of measurements, the CFD calculations were carried out and the static pressure at the impellers inlet passages were shown.

ə Open Access. ๑ 2019 J. Skrzypacz and M. Bieganowski, published by De Gruyter. 

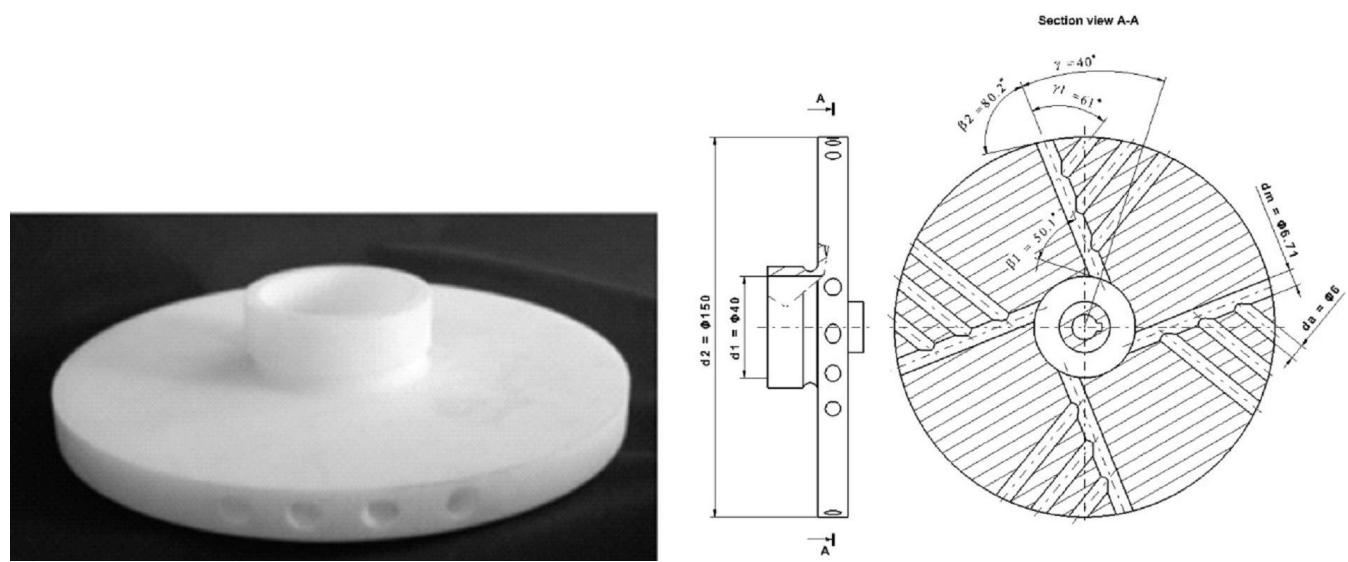

Figure 1: Geometry of the impeller 1 (I1)
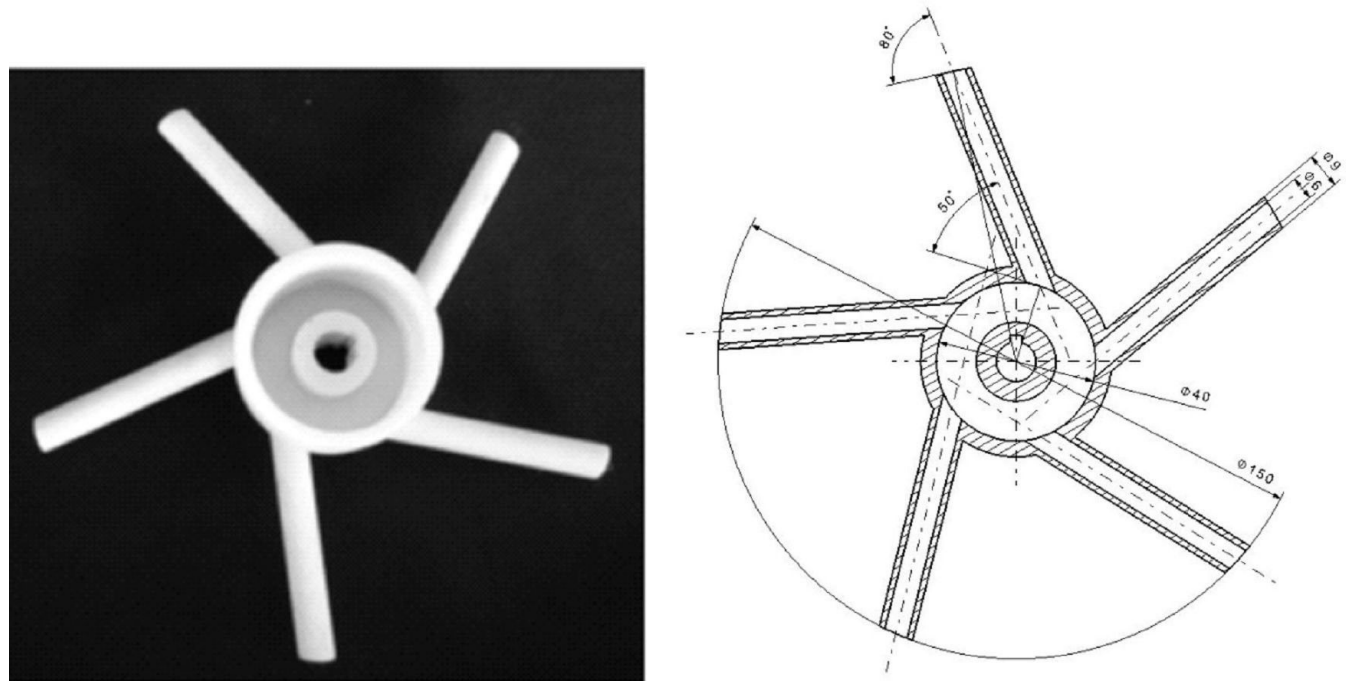

Figure 2: Geometry of the impeller 2 (I2)

Table 1: Design parameters of the impellers

\begin{tabular}{cccc}
\hline No & Parameter & Unit & Value \\
\hline \multicolumn{4}{c}{ Operation parameters } \\
1 & Flow rate & $Q\left[\mathrm{~m}^{3} / \mathrm{h}\right]$ & 4.5 \\
2 & Head & $H[\mathrm{~m}]$ & 27 \\
3 & Rotational speed & $n[\mathrm{rpm}]$ & 2870 \\
\hline
\end{tabular}

\section{Research objects}

The main objects of the research were four rotodynamic pump impellers, designed for working parameters presented in Table 1. All impellers were manufactured with SLS rapid prototyping method (Selective Laser Sintering), using DuraForm EX material described below:

- density (sintered part) $1.01 \mathrm{~g} / \mathrm{cm} 3$;

- flexural modulus $1310 \mathrm{MPa}$;

- flexural strength $46 \mathrm{MPa}$;

- tensile strength $48 \mathrm{MPa}$;

- elongation at break $47 \%$;

- hardness 74 shore.

Impeller 1 (I1). The first one (I1) was a drilled impeller with additional side holes. Such a structure is a developing of the commonly known idea of drilled impeller presented in [4]. Basic parameters were shown in the Figure 1.

Impeller 2 (I2). The second one (I2) was multi-piped impeller, designed according to patent [6]. Such structure was described in detail in [9]. The shape and basic parameters were presented in Figure 2.

Impeller 3(13). Impeller 3 is a modification of Impeller 2 where the number of the channels ( $z$ ) and external diameter $\left(\mathrm{d}_{2}\right)$ were decreased to $z=4$ and $d_{2}=130 \mathrm{~mm}$ respectively. The model was shown in the Figure 3. 
Table 2: Measuring instruments [9]

\begin{tabular}{cccc}
\hline No & Measuring instrument & Range & Accuracy class \\
\hline 1 & Electromagnetic flow meter Arkon & $0.18-17.67 \mathrm{~m}^{3} / \mathrm{h}$ & $0.2 \%$ \\
& MAGS1-ST DN25 PN 40 & $(0.1-10 \mathrm{~m} / \mathrm{s})$ & \\
2 & Pressure Gauge (suction) FUJI FKP 01 & $-0.7-0.5 \mathrm{bar}$ & $0.1 \%$ \\
3 & Pressure Gauge (discharge) FUII FKP 03 & $0-30 \mathrm{bar}$ & $0.1 \%$ \\
4 & Active Power Transducer METROL PP73 & $0-3000 \mathrm{~W}$ & $0.3 \%$ \\
5 & Temperature Transducer FLEXTOP 2202 & $0-50^{\circ} \mathrm{C}$ & $\pm 0.9^{\circ} \mathrm{C}$ \\
\hline
\end{tabular}

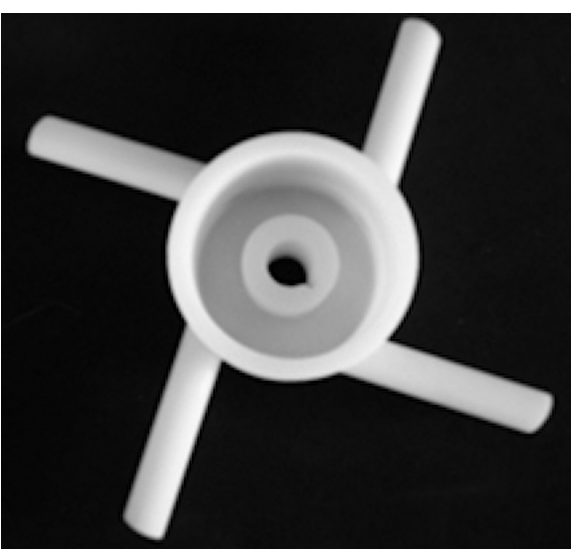

Figure 3: Geometry of the impeller 3 (13)

Impeller 4 (I4). Impeller 4 is a modification of Impeller 2 concept where the pipes that create impeller passages were bended in such way in order to obtain optimal values of the inlet and outlet angles. The number of passages is $z=4$, inlet angle $\beta_{1}=50$ deg., outlet angle $\beta_{2}=30$ deg.

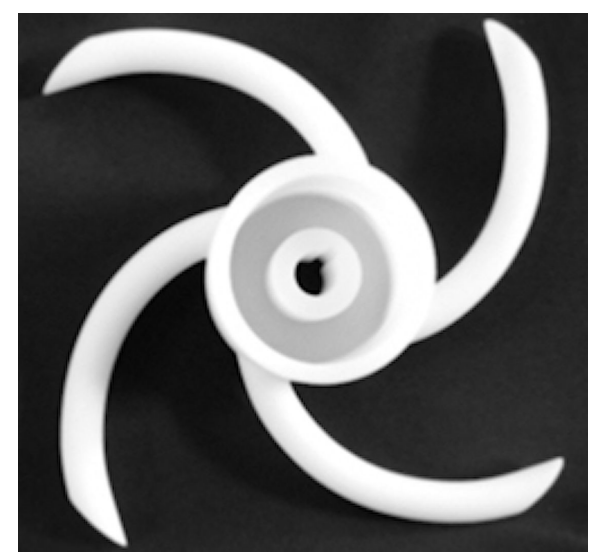

Figure 4: Geometry of the impeller 4 (14)

\section{Test rig}

In order to conduct investigation, a specialized test rig presented in Figure 5 - was designed and constructed [9]. The main element of the test rig is a pump (Figure $5 b$ ) with a special design allowing for the quick replacement of the tested impellers while maintaining the repeatability of the measurement results.

The pump is supplied from a closed tank where - depending upon the needs - one can generate overpressure or negative pressure and control the medium level and temperature.

The pump capacity can be adjusted with a ball control valve, namely MARS $88 \mathrm{~V}$ with an IntrOM OM-1 electric drive. The measuring instruments which parameters are presented in Table 2 were used for measuring the specific values.

The characteristics of the tested impeller were measured in a fully automated way, according to the recommendations given in EN IS0 9906:2000. The measurement process is controlled by a computer and dedicated software. The test rig gives possibility of cavitation research by means of three methods:

- generation vacuum in the tank,

- decrease water level in the tank,

- throttling at the suction pipeline.

The third method (throttling at the suction pipeline) was selected as the fastest and which generated accuracy on the acceptable level.

\section{Result of the measurements}

The basic parameters were determined according to following formulas:

Pump head:

$$
H=\frac{P_{m t}-P_{m s}}{\rho g}+\frac{c_{t}^{2}-c_{s}^{2}}{2 g},
$$


a)

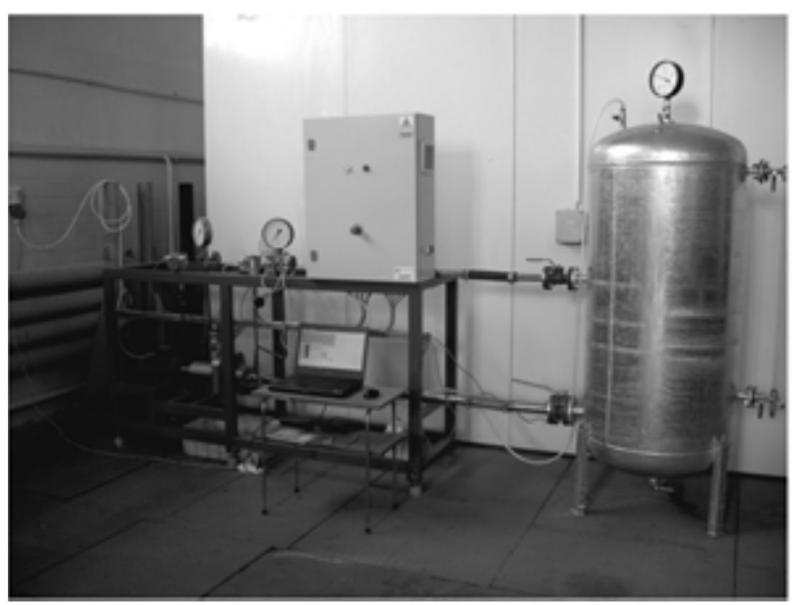

Figure 5: View of the test rig [9]

Hydraulic power:

$$
P_{U}=\rho \cdot g \cdot Q \cdot H
$$

Pump efficiency

$$
\eta=\frac{P_{U}}{P_{w}} .
$$

Net Positive Suction Head

$$
N P S H=\frac{p_{b}}{\rho g}+\frac{p_{m s}}{\rho g}+\Delta z_{s}+\frac{c_{s}^{2}}{2 g}-\frac{p_{v}}{\rho g}
$$

Required Net Positive Suction Head

$$
N P S H r=k \cdot N P S H
$$

Based on data presented in Table 1 the average measurement uncertainness were determined as follows:

- for pump head $\Delta H=4 \%$,

- for hydraulic power $\triangle P=8 \%$,

- for $N P S H \triangle N P S H=3 \%$.

The results of the measurements are presented in the Figures 6-13.

Based on the results presented above, we can formulate the following conclusions:

1. Only impeller 2 achieved the assumed operating parameters (Table 1).

2. The maximal efficiency was reached by impeller 1 and impeller 4, respectively.

3. For the flow rate $Q=4.5 \mathrm{~m}^{3} / \mathrm{h}$, the best cavitation performance achieved impeller $4(\mathrm{NPSHr}=8 \mathrm{~m})$, the worst - Impeller 1 (NPSHr $=10.5 \mathrm{~m}$ ).

4. The lowest value of NPSHr $=8 \mathrm{~m}$ (Impeller 4) is much higher than expected for classical centrifugal impeller (NPSHr=5.5 m - value obtained from author's research). b)

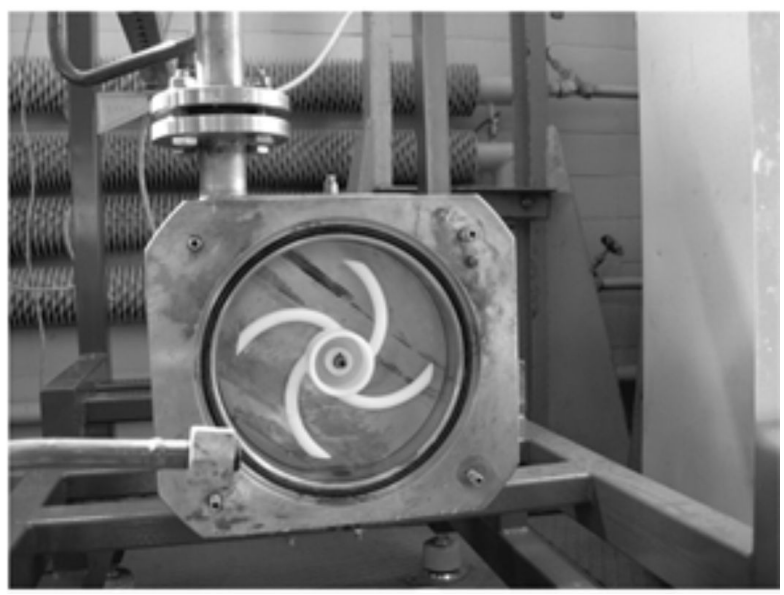

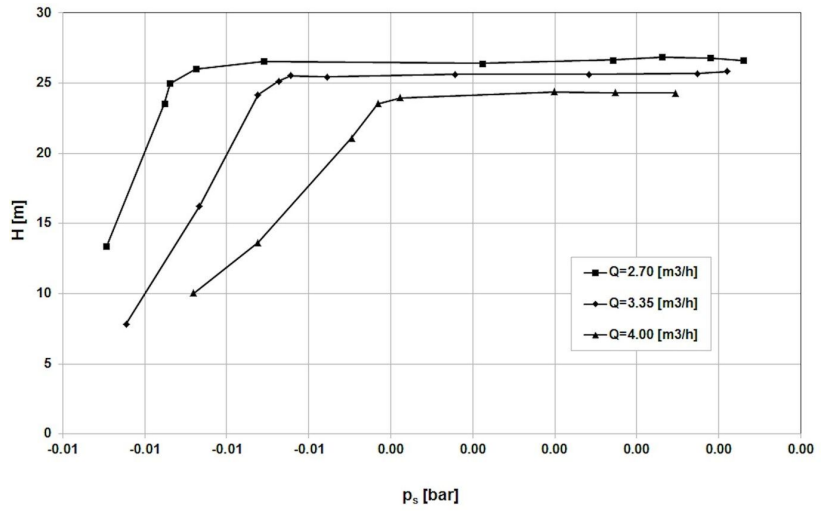

Figure 6: Cavitation curves of the Impeller 1

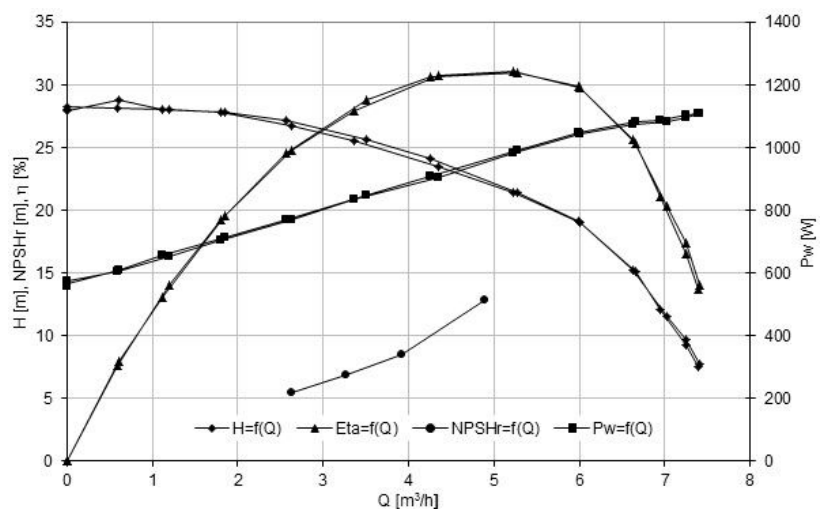

Figure 7: Characteristics of the Impeller 1

5. The shapes of the cavitation curves are typical for classical centrifugal impellers and double elbows do not appear as for impellers with large inlet attack angle [10]. 


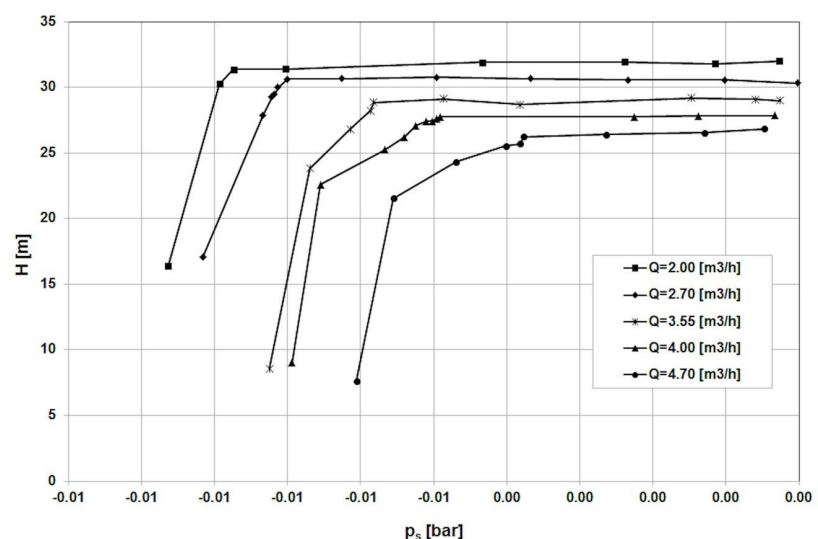

Figure 8: Cavitation curves of the Impeller 2

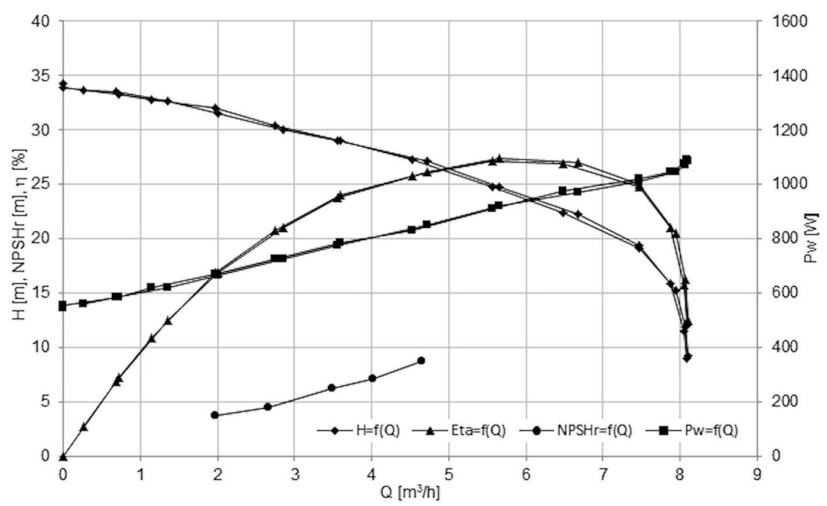

Figure 9: Characteristics of the Impeller 2

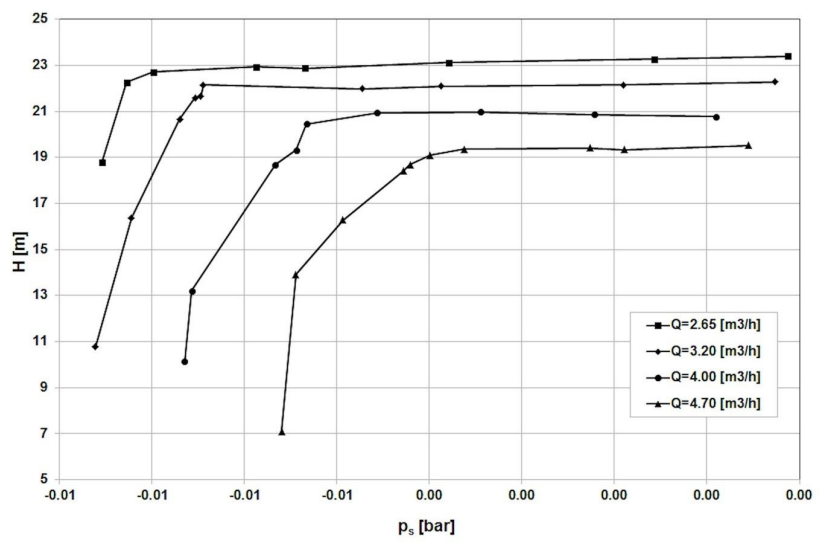

Figure 10: Cavitation curves of the Impeller 3

\section{CFD modeling}

In order to better understand cavitation behavior of the investigated impellers, the CFD calculations were performed for all impellers. The main aim of this calculations was to determine the static pressure distribution and to evaluate the pressure drop. Due to this fact, analysis were

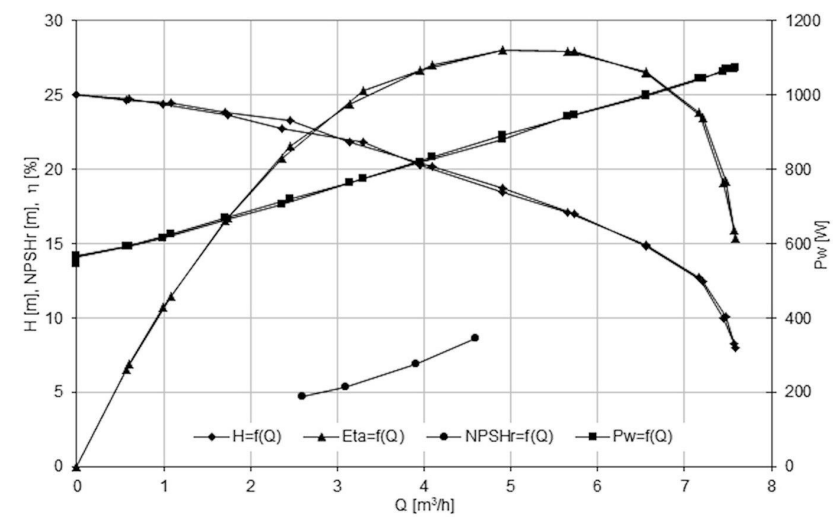

Figure 11: Characteristics of the Impeller 3

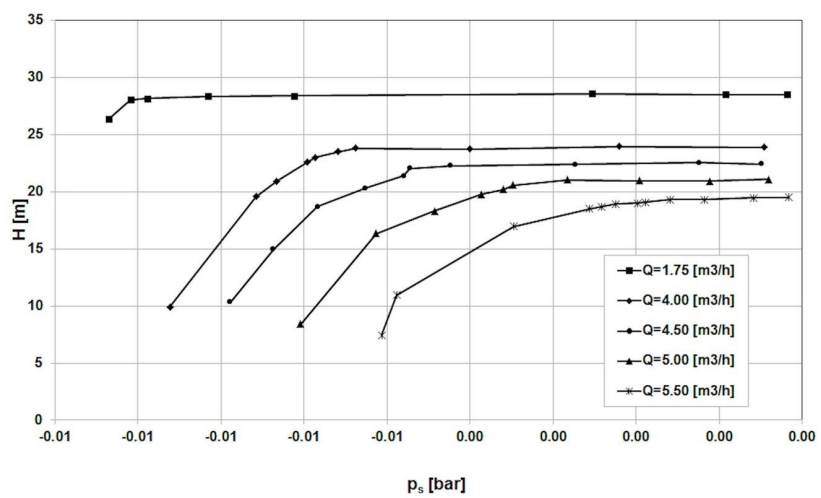

Figure 12: Cavitation curves of the Impeller 4

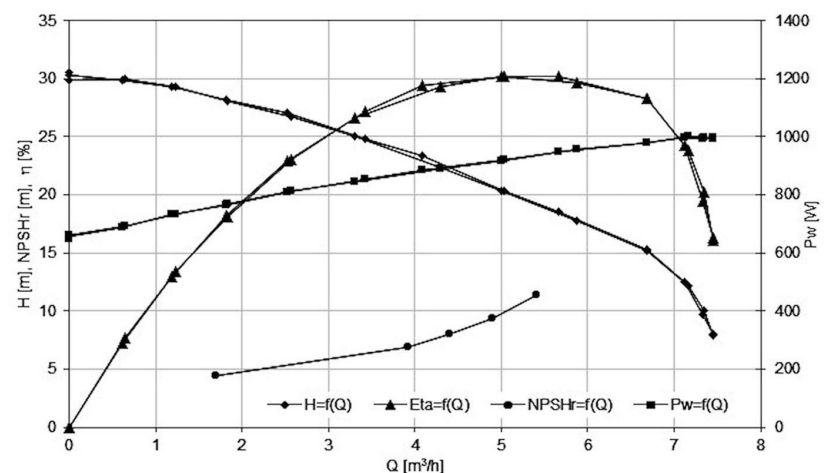

Figure 13: Characteristics of the Impeller 4

done without multiphase model. General description of the numerical model, applied grid, boundary conditions and rules of CFD modeling in detail one can find in [9]. In the Figures 14-17 the static pressure distribution was presented.

Based on presented results, we can formulate following conclusions:

1. In case of Impeller 1 additional pressure drop is observed in the inlet to the first side hole. This is the reason of the worst cavitation performance. 
2. The Impellers 3 and 4 have better cavitation performance than Impeller 2 (Figure 15). This confirms assumption that impellers with lower number of passages and larger area of the inlet cross-section work better (lower pressure drop at the inlet section - Figures 16-17).

3. The Impeller 4 has lower NPSHr than Impeller 3. It means that there is optimal value of the inlet angle $\beta_{1}$ from cavitation performance point of view (Figure 17) [10].
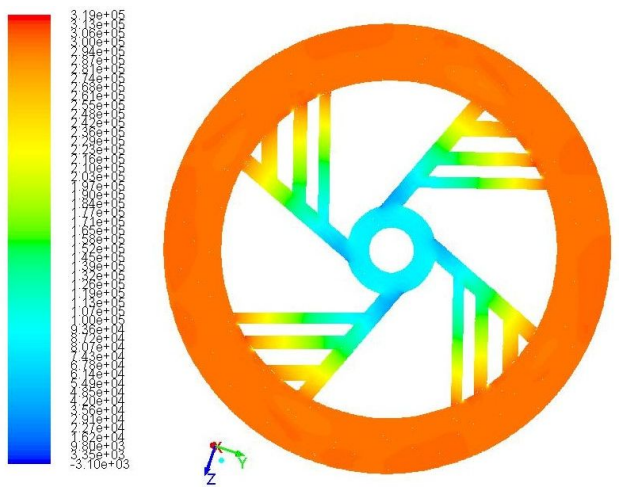

Figure 14: Static pressure distribution $[\mathrm{Pa}]$ in Impeller 1

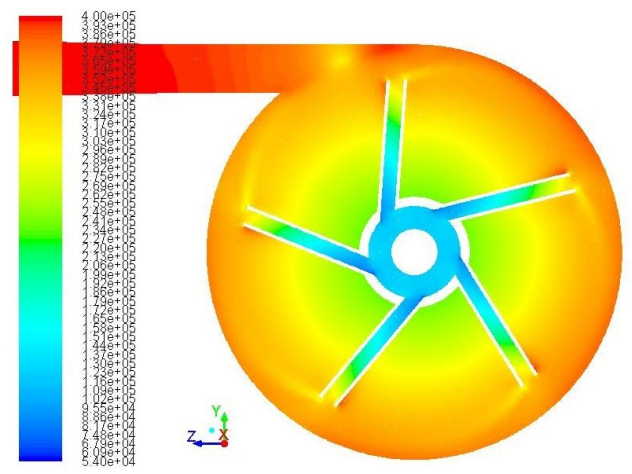

Figure 15: Static pressure distribution $[\mathrm{Pa}]$ in Impeller 2

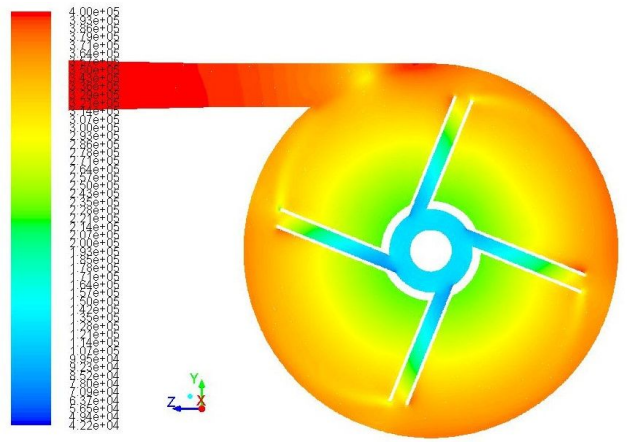

Figure 16: Static pressure distribution $[\mathrm{Pa}]$ in Impeller 3

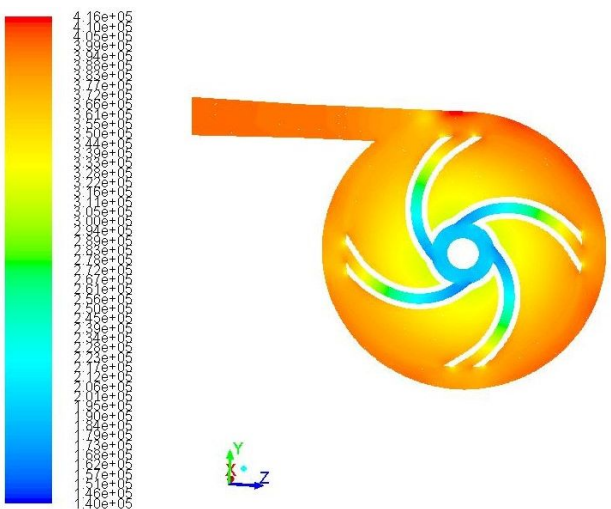

Figure 17: Static pressure distribution $[\mathrm{Pa}]$ in Impeller 4

\section{Summary}

Drilled impellers and multi-piped impellers are an interesting alternative for classical centrifugal impellers in the range of extremely low specific speed $\left(n_{q}<10\right)$. The values of the $\mathrm{NPSH}_{r}$ for all investigated impellers are much higher than for classical centrifugal impellers. Among the researched impellers the best one was Impeller 4 , that had 4 passages and the value of inlet angle $\beta_{1}$ within the optimal range [10].

Acknowledgement: Calculations have been carried out using resources provided by Wroclaw Centre for Networking and Supercomputing (http://wcss.pl), grant No. 444.

\section{References}

[1] Choi Y., Kurokawa J., Matsui J., Imamura H., Internal flow characteristics of a centrifugal pump with very low specific speed, XXI st IAHR Symposium on Hydraulic Machinery and Systems, Lausanne, 2002, 1-7

[2] Kagawa S., Choi Y., Kurokawa J., Matsumi J., Performance of very low specific speed centrifugal pumps with circular casing. J. of Fluid Sci. Technol., 2007, 2(1), 130-138. DOI: 10.1299/jfst.2.130

[3] Kurokawa J., Yamada T., Hiraga H., Performance of low specific speed pumps, $11^{\text {th }}$ Australasian Fluid Mechanics Conference, (1992, Australia, Hobart), Hobart, 1992, 861-864

[4] Gulich J, Centrifugal Pumps, Springer, Berlin, 2008

[5] Zhewen W., Round-disc through-hole ultra-low ratio rotary speed centrifugal pump, Patent CN101021215, 2007

[6] Skrzypacz J., Wirnik pompy wirowej (Impeller of rotodynamic pump), Patent PL 86135, 2008

[7] Skrzypacz J., Analiza pracy pompy z wirnikiem otworowym (Analysis of a drilled impeller pump operation), Pompy Pompownie 2(2008), 32-34.

[8] Skrzypacz J., Wpływ parametrów geometrycznych wirnika otworowego na proces przekazywania energii (Influence of geo- 
metrical features of a drilled impeller on the energy transfer process). (2008, Przemysl, Poland), XII Międzynarodowa Konferencja Naukowo-Techniczna HERVICON, Przemyśl, 2008, 227-234.

[9] Skrzypacz J., Numerical modelling of flow phenomena in a pump with a multi-piped impeller, Chem. Eng. Processing: Process Intensification, 75, 2014, 58-66. DOI: 10.1016/j.cep.2013.11.003.
[10] Misiewicz A., Skrzypacz J., Cavitation behaviours of low specific speed pump impellers designed according to the "tight inlet" rule, Cent. Eur. J. Eng., 1(2), 2011, 195-201. DOI: 10.2478/s13531011-0019-4. 